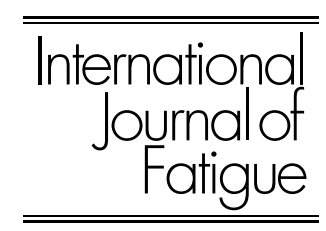

www.elsevier.com/locate/ijfatigue

\title{
Partial crack closure under block loading
}

\author{
L.P. Borrego ${ }^{\mathrm{a}, *}$, J.M. Ferreira ${ }^{\mathrm{b}}$, J.M. Costa $^{\mathrm{b}}$ \\ ${ }^{a}$ Department of Mechanical Engineering, ISEC, Rua Pedro Nunes, Quinta da Nora, 3030-199 Coimbra, Portugal \\ ${ }^{\mathrm{b}}$ Department of Mechanical Engineering, University of Coimbra, Polo II, Pinhal de Marrocos, 3030-201 Coimbra, Portugal
}

Received 23 October 2007; received in revised form 11 February 2008; accepted 20 February 2008

Available online 4 March 2008

\begin{abstract}
Fatigue crack propagation tests under high-low and low-high block loading sequences have been performed in aluminium alloy specimens. The tests were carried out at constant $\Delta K$ conditions. Two stress ratios were analysed: $R=0.05$ and $R=0.4$. Crack closure was monitored in all tests by the compliance technique using a pin microgauge. The observed transient post load step behaviour is discussed in terms of the load change magnitude, $\Delta K$ baseline levels and stress ratio. The crack closure level was obtained and compared with the crack growth transients. A good agreement between experimental and predicted crack growth rates is obtained when the partial crack closure effect is properly taken into account. Therefore, plasticity-induced crack closure plays an important role on the load interaction effects observed in aluminium alloys.
\end{abstract}

(C) 2008 Elsevier Ltd. All rights reserved.

Keywords: Aluminium alloy; Fatigue crack growth; Block loading; Crack closure; Partial crack closure

\section{Introduction}

Service conditions generally involve random or variable amplitude, rather than constant amplitude loads. Significant accelerations and/or retardations in crack growth rate can occur as a result of these load variations. Thus, an accurate prediction of fatigue life requires an adequate evaluation of these load interaction effects. To attain this objective several type of simple variable amplitude load sequences must be analysed. However, the majority of the work carried out in this field has been on the effects of single peak tensile overloads, e.g. [1,2], simply because this type of loading can lead to significant load interaction effects. Furthermore, the precise micromechanisms responsible for these effects are not fully understood.

Generally, under constant amplitude loading, closure measurements produce good correlation between low stress ratio and high stress ratio crack growth rate data, e.g. [3-5], through the effective range of $K$ corresponding to a fully open crack, $\Delta K_{\text {eff }}$, introduced by Elber [3],

\footnotetext{
${ }^{*}$ Corresponding author. Tel.: +351 962560101; fax: +351 239790331.

E-mail address: borrego@isec.pt (L.P. Borrego).
}

$\Delta K_{\mathrm{eff}}=K_{\mathrm{max}}-K_{\mathrm{op}}$

where $K_{\max }$ is the stress intensity at maximum load and $K_{\mathrm{op}}$ is the stress intensity value at opening load.

However, at the near-threshold regime the measured opening loads are some times excessively high because the role of the lower portion of the loading cycle below $K_{\text {op }}$ to the fatigue crack growth behaviour is not taken into account, e.g. [6-8], resulting in a significant underestimation of the effective crack driving force. Additionally, under single peak overloads some discrepancies appear when the experimental post-overload transients are compared with crack growth rates inferred from remote closure measurements and the $\mathrm{d} a / \mathrm{d} N$ versus $\Delta K_{\text {eff }}$ relation for the material [9-13]. Among other observations, these behaviours have contributed for some of the controversy around the phenomenon of crack closure.

\section{Partial crack closure}

Recently, Paris et al. [14] and Donald and Paris [15] introduced the concept of partial closure. According to this concept contact between crack faces can occur while still 
leaving the crack tip open and able to elastically unload as the load is further reduced. Therefore, a significant contribution to fatigue damage occurs in the load range below the opening load when measured remotely from the crack tip by the compliance technique. Considering that even those that have questioned the assumption of plasticityinduced closure [16] do not object to crack surface interference caused by mismatched roughness, Paris et al. [14] proposed the partial closure model. This model suggests that the effective $\Delta K$ could be bounded by

$K_{\max }-\frac{2}{\pi} K_{\mathrm{op}}-\left(1-\frac{2}{\pi}\right) K_{\min } \leqslant \Delta K_{\mathrm{eff}} \leqslant K_{\max }-\frac{2}{\pi} K_{\mathrm{op}}$

Therefore, an approximate result of the effective range of $K$, between its real minimum and maximum, could be given by the following simple expression

$\Delta K_{\text {eff }}=K_{\max }-\frac{2}{\pi} K_{\text {op }}$

In spite of an apparent slight overestimation of $\Delta K_{\mathrm{eff}}$ by Eq. (3), experimental results showed that, for several aluminium alloys under constant amplitude loading, this concept demonstrates a significant improvement in the correlation of $R$-ratio effects at the near-threshold regime $[14,15]$. Incidentally, Newman [17] has also indicated that under conditions of remote (partial) closure the appropriate opening stress to calculate the effective stress range is $0.62 \sigma_{\mathrm{op}}$, which is very close to $2 / \pi \sigma_{\mathrm{op}}$.

It is important to notice that the partial closure model was physically established assuming that, under $\Delta K$ reduction simulations, the crack is open at the tip and closed near the load reduction location at loads below the crack opening load, which induces measurements of crack opening loads that are excessively high [14]. On the other hand, under single tensile overloads, an enlarged hump of residual stretched material is formed ahead of the overload location [11]. The asperities of residual plastic wake left by the overload are so large that they will come into contact even when the crack tip is still fully open $[11-13,18]$ as depicted in Fig. 1. The stretched material of the residual hump acts like a compliant spring and allows cyclic crack tip displacements to occur at loads below the crack opening load [11], thus, promoting partial crack closure.

Therefore, in previous work [19] the partial closure model, namely Eq. (3), established for constant amplitude loading, was used to predict post-overload transients from far field closure measurements. However, it was clear that there was a significant transition period from the conditions of full crack closure to partial crack closure, which is not taken into account by the partial closure model. Thus, a correction factor is needed in Eq. (3) to consider this transition period. For this purpose, it was suggested that Eq. (3) can be rewritten with the following modification:

$\Delta K_{\mathrm{eff}}=K_{\max }-\frac{2}{\pi} F^{*} K_{\mathrm{op}}$

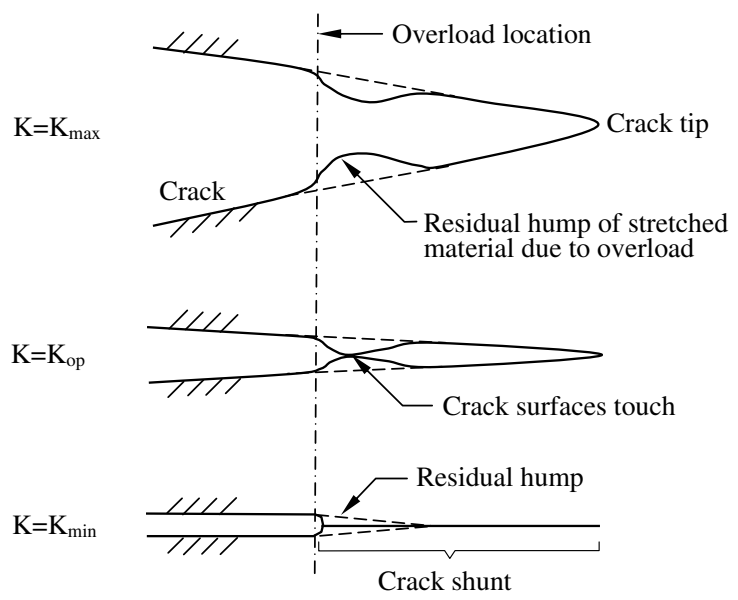

Fig. 1. The phenomenon of partial closure under a single tensile overload, after Fleck [11].

where $F^{*}$ is a transition function associated with the crack tip opening profile and, thus, with the crack length after the load variation event, $a^{*}$. Defining $a_{1}^{*}$ and $a_{2}^{*}$ as the crack tip increments from the load variation event corresponding to the beginning and ending of the transition period, respectively, $F^{*}$ has to be equal to $\pi / 2$ for $a^{*}=a_{1}^{*}, 1$ for $a^{*} \geqslant a_{2}^{*}$ and must decay asymptotically from $\pi / 2$ to 1 when $a^{*}$ approaches $a_{2}^{*}$, i.e.,

$$
\left\{\begin{array}{l}
F^{*}\left(a_{1}^{*}\right)=\frac{\pi}{2} \\
F^{*}\left(a_{2}^{*}\right) \approx 1 \\
\lim _{a^{*} \rightarrow \infty} F^{*}\left(a^{*}\right)=1
\end{array}\right.
$$

When meeting these conditions Eq. (4) is reduced to Eq. (1) for crack lengths from the load variation event less than $a_{1}^{*}$ and reduced to Eq. (3) at crack lengths higher than $a_{2}^{*}$, evolving from the conventional Elber's closure approach to the partial closure model in between. Incidentally, Kujawski [20] also proposed a similar approach to evolve from partial crack closure near threshold to a condition of full crack closure in the Paris region under constant amplitude loading.

Considering an exponential decay, the following expression was proposed for $F^{*}[19]$

$F^{*}\left(a^{*}\right)=1+\left(\frac{\pi}{2}-1\right) \mathrm{e}^{-\pi \xi}$

which ensures that $F^{*}\left(a_{2}^{*}\right)=1$ with a deviation smaller than $2.5 \%$. In Eq. (6) $\xi$ represents the fraction between the crack length after the appearance of partial closure and the length of the transition period:

$\xi=\frac{a^{*}-a_{1}^{*}}{a_{2}^{*}-a_{1}^{*}}$

Previous work [19] performed a detailed analysis of the effect of single overloads with several overload intensities, stress ratios and $\Delta K$ baseline levels under constant $\Delta K$ conditions. Fig. 2 shows that the analysis of the crack closure 
data available indicates that the point where partial closure starts correlates well with a crack length $a_{1}^{*}$ of about half the size of the overload plastic zone, $r_{\mathrm{p}}$, evaluated from

$r_{\mathrm{p}}=\frac{1}{\pi}\left(\frac{K_{\mathrm{OL}}}{\sigma_{\mathrm{YS}}}\right)^{2}$

where $K_{\mathrm{OL}}$ is the stress intensity factor at peak load during the overload cycle and $\sigma_{\mathrm{YS}}$ is the yield stress. This plastic zone superimposes the plastic zone created during regular crack growth at constant amplitude fatigue. Furthermore, Fig. 2 shows that the transition period seems to occur until a crack increment after the load variation event of approximately $a_{2}^{*}=\pi / 2 \times r_{\mathrm{p}}$ is reached. Consequently, Eq. (7) can be approximated by

$\xi=\frac{2 a^{*}-r_{\mathrm{p}}}{r_{\mathrm{p}}(\pi-1)}$

and the transition function (Eq. (6)) can now be defined as

$F^{*}=1+\left(\frac{\pi}{2}-1\right) \mathrm{e}^{-\pi\left(\frac{2 a^{*}-r_{\mathrm{p}}}{r_{\mathrm{p}}(\pi-1)}\right)}$

Thus, using the transition function as defined by Eq. (10), the transition period from full crack closure to partial crack closure conditions under variable amplitude loading can be taken into account by simply calculating the monotonic plastic zone size induced by the load variation. Finally, it is important to notice that Eq. (10) was established for constant $\Delta K$ conditions.

The enhanced partial closure approach, Eqs. (4) and (10), demonstrated a significant improvement in the correlation of experimental post-overload crack growth transients and inferred crack growth rates from far field crack closure measurements [19].

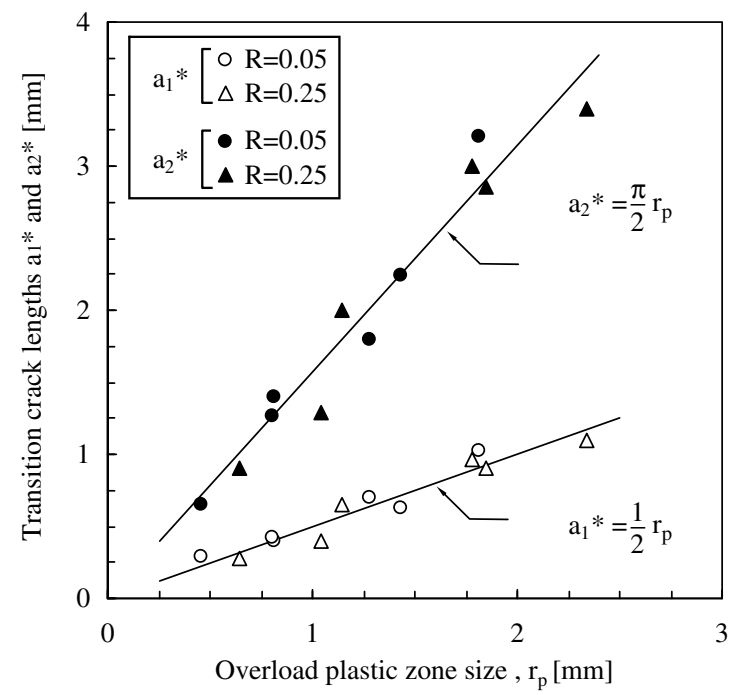

Fig. 2. Variation of the characteristic transition crack lengths between the conditions of full crack closure and partial crack closure against $r_{\mathrm{p}}$ under single tensile overloads using the data presented in Ref. [19].
Fatigue tests under block loading sequences [21,22] have confirmed that load step-down in a Hi-Lo block can also cause crack growth retardation. Therefore, the present work intends to analyse the fatigue crack growth on aluminium alloy specimens subjected to high-low (Hi-Lo) and low-high (Lo-Hi) block loading sequences, and evaluate if the observed transient crack growth behaviour can be correlated with the crack closure phenomenon when the partial crack closure effect is correctly accounted for.

\section{Experimental details}

The material used in this research was an AlMgSil (6082) aluminium alloy with T6 heat treatment. The T6 heat treatment corresponds to a conversion of heat-treatable material to the age-hardened condition by solution treatment, quenching and artificial age-hardening. The alloy chemical composition and mechanical properties are shown in Tables 1 and 2, respectively.

Fatigue tests were conducted, in agreement with ASTM E647 standard [24], using middle-tension, $M(T)$, specimens with $3 \mathrm{~mm}$ thickness. The specimens were obtained in the longitudinal transverse (LT) direction from a laminated plate. Fig. 3 illustrates the major dimensions of the samples used in the tests. The notch preparation was made by electrical-discharge machining. After that, the specimen surfaces were mechanically polished.

All experiments were performed in a servo-hydraulic, closed-loop mechanical test machine with $100 \mathrm{kN}$ load capacity, interfaced to a computer for machine control and data acquisition. All tests were conducted in air, at room temperature and with a load frequency of $15 \mathrm{~Hz}$. The specimens were clamped by hydraulic grips. The crack length was measured using a travelling microscope $(45 \times)$ with a resolution of $10 \mu \mathrm{m}$. Collection of data were initiated after achieving an initial crack length $2 a_{0}$ of approximately $12 \mathrm{~mm}$.

The tests were performed under constant $\Delta K$ and stress ratio, $R$, conditions, by manually shedding the load with crack growth. The load shedding intervals were chosen so that the maximum $\Delta K$ variation was smaller than $2 \%$. After each load step the associated transient crack growth behaviour was carefully observed. The influence of the load blocks was investigated under high-low (Hi-Lo) and low-high (Lo-Hi) sequences, at $\Delta K$ baseline levels of 6,9 and $12 \mathrm{MPa} \mathrm{m}^{1 / 2}$, and at two different stress ratios, $R=0.05$ and $R=0.25$. The crack growth rates were determined by the secant method [24].

Load-displacement behaviour was monitored at specific intervals throughout each of the tests using a pin microgauge elaborated from a high sensitive commercial axial

Table 1

Chemical composition of 6082-T6 aluminium alloy (wt.\%)

\begin{tabular}{lllllllll}
\hline $\mathrm{Si}$ & $\mathrm{Mg}$ & $\mathrm{Mn}$ & $\mathrm{Fe}$ & $\mathrm{Cr}$ & $\mathrm{Cu}$ & $\mathrm{Zn}$ & $\mathrm{Ti}$ & Other \\
\hline 1.05 & 0.80 & 0.68 & 0.26 & 0.01 & 0.04 & 0.02 & 0.01 & 0.05 \\
\hline
\end{tabular}


Table 2

Mechanical properties of 6082-T6 aluminium alloy [23]

Tensile strength, $\sigma_{\mathrm{UTS}}(\mathrm{MPa})$

$300 \pm 2.5$

Yield strength, $\sigma_{\mathrm{YS}}(\mathrm{MPa})$

Elongation, $\varepsilon_{\mathrm{r}}(\%)$

Cyclic hardening exponent, $n^{\prime}$

Cyclic hardening coefficient, $K^{\prime}(\mathrm{MPa})$

Fatigue strength exponent, $b$

Fatigue strength coefficient, $\sigma_{\mathrm{f}}^{\prime}(\mathrm{MPa})$

Fatigue ductility exponent, $c$

Fatigue ductility coefficient, $\varepsilon_{\mathrm{f}}^{\prime}$

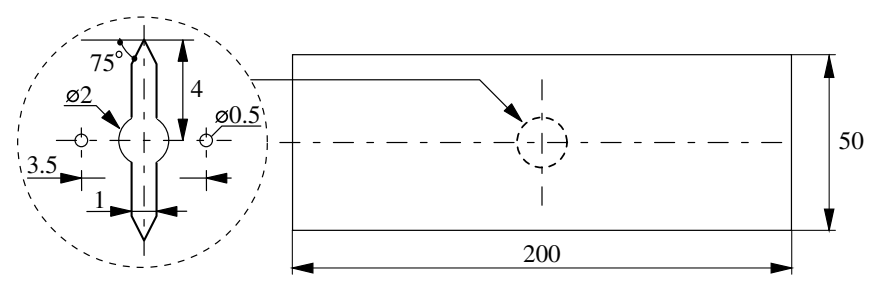

Fig. 3. Geometry of the $M(T)$ specimen (dimensions in $\mathrm{mm}$ ).

extensometer $( \pm 0.625 \mathrm{~mm}$ of maximum displacement). Details of the full process used to obtain the crack closure level, as well as the sensitivity of pin gauge location with respect to the crack tip are reported elsewhere [25]. The gauge pins were placed in two drilled holes of $0.5 \mathrm{~mm}$ diameter located above and below the centre of the notch (see Fig. 3). The distance between these holes was $3.5 \mathrm{~mm}$. In order to collect as much load-displacement data as possible during a particular cycle, the frequency was reduced to $0.5 \mathrm{~Hz}$. Noise on the strain gauge output was reduced by passing the signal through a $1 \mathrm{~Hz}$ low-pass mathematical filter.

From the load-displacement records, variations of the opening load, $P_{\text {op }}$, were derived using the technique known as maximization of the correlation coefficient [26]. This technique involves taking the upper $10 \%$ of the load-displacement data and calculating the least squares correlation coefficient. The next data pair is then added and the correlation coefficient is again computed. This procedure is repeated for the whole dataset. The point at which the correlation coefficient reaches a maximum can then be defined as $P_{\mathrm{op}}$.

The fraction of the load cycle for which the crack remains fully open, parameter $U$, was calculated by the following equation:

$U=\frac{P_{\max }-P_{\mathrm{op}}}{P_{\max }-P_{\min }}$

After each test the fatigued fracture surfaces were observed in a Philips XL30 scanning electron microscope.

\section{Results and discussion}

\subsection{Transient crack growth behaviour}

Fig. 4 shows the typical transient crack growth behaviour obtained when a specimen is subjected to a $\mathrm{Hi}-\mathrm{Lo}$

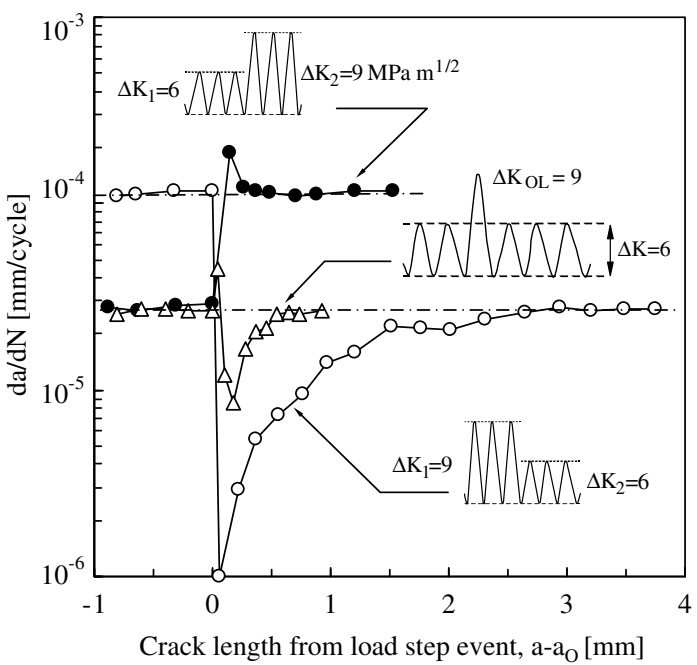

Fig. 4. Transient behaviour following a single tensile overload, a Hi-Lo block and a Lo-Hi block.

or a Lo-Hi block in a constant $\Delta K$ test. In this figure the crack growth rate is plotted against the crack length from the load step event, $a-a_{\mathrm{O}}$, i.e., $a^{*}$, where $a_{\mathrm{O}}$ is the crack length at which the change in load is applied. The results presented in Fig. 4 were obtained for a load step applied in the Paris regime, with a difference between the initial $\Delta K$ level, $\Delta K_{1}$, and the final one, $\Delta K_{2}$, of $3 \mathrm{MPa} \mathrm{m}{ }^{1 / 2}$. The transient crack growth behaviour due to an equivalent single tensile overload $(50 \%$ overload applied at $\Delta K=6 \mathrm{MPa} \mathrm{m}^{1 / 2}$ ), obtained in previous work [19], is also plotted in the figure for comparison.

Similarly as for overloads, the magnitude and extent of retardation can be quantified by the crack growth increment affected by the step in load, $\Delta a_{\mathrm{O}}$, and by the delay cycles, $N_{\mathrm{D}}$. The parameter $\Delta a_{\mathrm{O}}$ is the crack growth distance between the point of load variation and the one at which the crack growth rate reaches the steady-state level corresponding to $\Delta K_{2},(\mathrm{~d} a / \mathrm{d} N)_{\Delta K_{2}} . N_{\mathrm{D}}$ is the difference between the number of cycles at which growth to steady-state $\Delta K_{2}$ level is achieved and the number of cycles that would occur, for the same loading conditions and crack length, if no load variation was applied.

Fig. 4 shows that there is a brief initial acceleration of crack growth rate immediately after the overload. The subsequent crack growth rate decreases until its minimum value is reached, followed by a gradual approach to the level of the baseline steady-state. The observed behaviour is usually referred to as delayed retardation of crack growth. The effect of the Hi-Lo block is similar to that observed for the peak overload. However, for this load sequence, the retardation is always immediate and not preceded by the acceleration phase. The Lo-Hi sequence produces an acceleration of crack growth rate, above the steady state level expected for the high block, followed by a gradual reduction to the corresponding steady-state $\Delta K_{2}$ level. This behaviour is identical to that generally observed following an underload [27]. The trends illus- 
trated in Fig. 4 are consistent with the behaviour normally reported in the literature $[1,21,22]$.

For the overload $\Delta a_{\mathrm{O}}=0.92 \mathrm{~mm}$ and $N_{\mathrm{D}}=12865$ cycles, while for the Hi-Lo block $\Delta a_{\mathrm{O}}=2.95 \mathrm{~mm}$ and $N_{\mathrm{D}}=179.773$, representing an increase in life of approximately fourteen times. Also, the minimum value of the crack growth rate reached during the retardation phase decreases from 0.32 (overload) to 0.034 (Hi-Lo block) relatively to the final $\mathrm{d} a / \mathrm{d} N$ baseline level. Moreover, the crack retardation is even higher for the $\mathrm{Hi}-\mathrm{Lo}$ sequence with $\Delta K_{1}=9 \mathrm{MPa} \mathrm{m}{ }^{1 / 2}$ and $\Delta K_{2}=6 \mathrm{MPa} \mathrm{m}^{1 / 2}$, than for a $100 \%$ overload $\left(\Delta a_{\mathrm{O}}=2.52 \mathrm{~mm}\right.$ and $N_{\mathrm{D}}=87.400$ cycles $)$ [19]. Therefore, the magnitude and extent of crack retardation are much higher for the load step-down than for the equivalent single tensile overload. A similar trend was also observed by Ng' Ang'a and James [22] in the EN8 steel. The accelerated crack growth rate produced by the Lo-Hi block persisted during approximately 3.600 cycles and the crack increment affected by this load variation was $0.35 \mathrm{~mm}$.

The characteristic features of the crack growth transients due to Hi-Lo blocks, Lo-Hi blocks and blocks resulting from a change in stress ratio, are summarized in Table 3. In addition to the parameters $\Delta a_{\mathrm{O}}$, and $N_{\mathrm{D}}$, this table also shown the minimum or maximum normalised crack growth rate achieved during the transient period, $(\mathrm{d} a / \mathrm{d} N)_{\min } /(\mathrm{d} a / \mathrm{d} N)_{\Delta K_{2}}$ or $(\mathrm{d} a / \mathrm{d} N)_{\max } /(\mathrm{d} a / \mathrm{d} N)_{\Delta K_{2}}$, respectively.

\subsection{Influence of the magnitude and position of the load step}

Figs. 5a and $\mathrm{b}$ present the influence of the magnitude and position of the load step in block loading for Hi-Lo and Lo-Hi block sequences, respectively.

For the load step from $\Delta K_{1}=12$ to $\Delta K_{2}=6 \mathrm{MPa} \mathrm{m}^{1 / 2}$ there was no crack growth after $5 \times 10^{5}$ cycles of further loading, showing that the crack was initially arrested under such load step-down. Therefore, crack growth retardation is enhanced by increasing the initial stress intensity relative to the final stress intensity range, i.e., the magnitude of the load step-down. The behaviour observed for this Hi-Lo block $\left(\Delta K_{2} / \Delta K_{1}=0.5\right)$ is in agreement with the experimental results of Sehitoglu and McDiarmid [21], where nonpropagating cracks occurred in mild steel for load step ratios, $\Delta K_{2} / \Delta K_{1}$, less than 0.6 .

Under block sequences with the same decrease in load ( $3 \mathrm{MPa} \mathrm{m}^{1 / 2}$ ), the crack growth increment affected by load reduction increased from $\Delta a_{\mathrm{O}}=2.95 \mathrm{~mm}$ to $\Delta a_{\mathrm{O}}=$ $4.83 \mathrm{~mm}$ when $\Delta K_{2} / \Delta K_{1}$ increased from $0.67\left(\Delta K_{1}=9\right.$ and $\left.\Delta K_{2}=6 \mathrm{MPa} \mathrm{m}^{1 / 2}\right)$ to $0.75\left(\Delta K_{1}=12\right.$ and $\Delta K_{2}=$ $9 \mathrm{MPa} \mathrm{m}^{1 / 2}$ ). However, for the same load conditions $N_{\mathrm{D}}$ decreased from 179.733 to 41.055 cycles (see Table 3 ). Therefore, in spite of the larger monotonic plastic zone established by the higher initial $\Delta K$, the crack growth rate is slower for the lower $\Delta K_{2}$, namely the minimum $\mathrm{d} a / \mathrm{d} N$ achieved during the transition period (see Table 3), resulting in the increase of retardation with the $\Delta K_{2}$ decrease.

Similarly, Fig. 5b and Table 3 show that for Lo-Hi sequences the acceleration during the crack growth transition phase increased with the final $\Delta K$. Furthermore, a smaller acceleration of the crack is observed for $\Delta K_{2} /$ $\Delta K_{1}=2\left(\Delta K_{1}=6\right.$ and $\left.\Delta K_{2}=12 \mathrm{MPa} \mathrm{m}^{1 / 2}\right)$ than for $\Delta K_{2} /$ $\Delta K_{1}=1.3\left(\Delta K_{1}=9\right.$ and $\left.\Delta K_{2}=12 \mathrm{MPa} \mathrm{m}^{1 / 2}\right)$ indicating also an increase of the acceleration with $\Delta K_{1}$. In any case, the initial acceleration due to the Lo-Hi sequences $(<820$ cycles) is much lower than the retardation induced by the Hi-Lo blocks analysed ( $>40.000$ cycles).

\subsection{Stress ratio effect}

The influence of the mean stress on the transient crack growth behaviour following a load step in $\mathrm{Hi}-\mathrm{Lo}$ and Lo-Hi block sequences is illustrated in Figs. 6a and b, respectively.

Table 3

Features of the crack growth transients

\begin{tabular}{|c|c|c|c|c|c|c|c|c|}
\hline Load sequence & $\frac{\Delta K_{1}}{\Delta K_{2}}$ & $\Delta K_{1}\left(\mathrm{MPa} \mathrm{m}^{1 / 2}\right)$ & $\Delta K_{2}\left(\mathrm{MPa} \mathrm{m}^{1 / 2}\right)$ & $R_{1}$ & $R_{2}$ & $\Delta a_{\mathrm{O}}(\mathrm{mm})$ & $N_{\mathrm{D}}$ (cycles) & $\frac{(\mathrm{d} a / \mathrm{d} N)_{\min (\max )}}{(\mathrm{d} a / \mathrm{d} N)_{\Delta K_{2}}}$ \\
\hline \multirow{4}{*}{$\Delta \mathrm{K}_{1}$} & 0.67 & 9 & 6 & 0.05 & 0.05 & 2.95 & 179.733 & 0.034 \\
\hline & 0.75 & 12 & 9 & 0.05 & 0.05 & 4.83 & 41.055 & 0.160 \\
\hline & 0.50 & 12 & 6 & 0.05 & 0.05 & \multicolumn{3}{|c|}{ No crack growth after $5 \times 10^{5}$ cycles } \\
\hline & 0.67 & 9 & 6 & 0.40 & 0.40 & 3.49 & 60.302 & 0.042 \\
\hline \multirow[t]{4}{*}{ Lo-Hi } & 1.5 & 6 & 9 & 0.05 & 0.05 & 0.48 & $-478^{\mathrm{a}}$ & 1.65 \\
\hline & 1.3 & 9 & 12 & 0.05 & 0.05 & 0.95 & -819 & 2.47 \\
\hline & 2.0 & 6 & 12 & 0.05 & 0.05 & 0.63 & -612 & 1.73 \\
\hline & 1.5 & 6 & 9 & 0.40 & 0.40 & 0.30 & -180 & 1.66 \\
\hline$\Delta \mathrm{K}_{1} \mathrm{MWWN} \mathrm{MWM}^{\Delta \mathrm{K}_{2}}$ & 1 & 6 & 6 & 0.05 & 0.40 & 0.74 & -1.555 & 1.66 \\
\hline 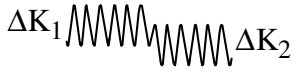 & 1 & 6 & 6 & 0.40 & 0.05 & \multicolumn{3}{|c|}{ No crack growth after $5 \times 10^{5}$ cycles } \\
\hline
\end{tabular}

\footnotetext{
a The minus sign indicates that the number of cycles for the respective sequence is lower than only in $\Delta K_{2}$.
} 

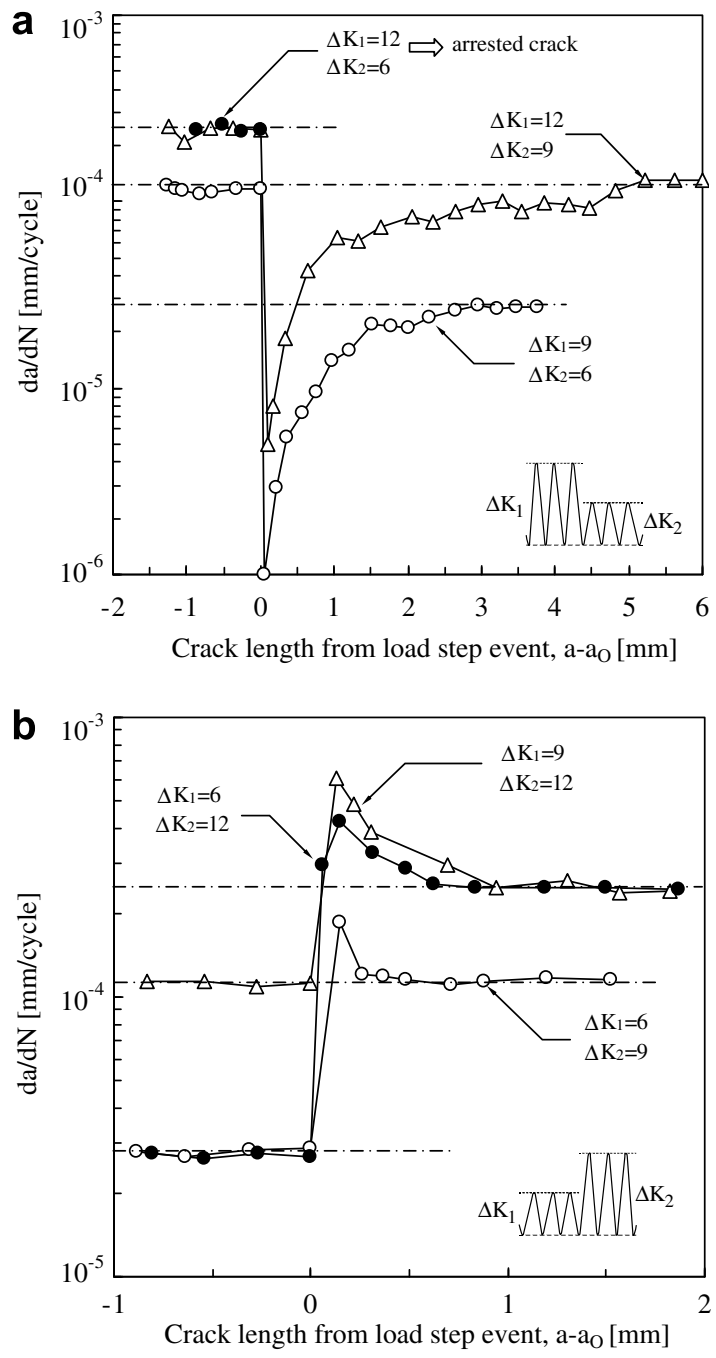

Fig. 5. Influence of the magnitude and position of load step: (a) Hi-Lo blocks and (b) Lo-Hi blocks.

Fig. 6a shows that the crack growth increment affected by the step in load is increased, although only slightly, when the stress ratio increases from 0.05 to 0.4 (see Table 3). However, a significant reduction of the delay cycles with increasing $R$ is observed (from $N_{\mathrm{D}}=179.733$ to $N_{\mathrm{D}}=60.302$ ). Therefore, similar to the generally observed behaviour in tensile overloads $[2,5,13,19]$, the retardation effect is reduced with increasing stress ratio.

Fig. 6a shows that for the load sequence with a stress ratio reduction from $R_{1}=0.4$ to $R_{2}=0.05$ the crack was arrested. Sehitoglu and McDiarmid [21] observed at $R=0$ non-propagating cracks for $\Delta K_{2} / \Delta K_{1}=0.6$ and propagating ones for $\Delta K_{2} / \Delta K_{1}=0.7$, concluding, as already mentioned, that non-propagating cracks occur after load steps with $\Delta K_{2} / \Delta K_{1} \leqslant 0.6$. Later on, at positive stress ratios, McDiarmid et al. [28] observed dormant cracks for maximum stress intensity factor step-down ratios, $K_{\max 2} / K_{\max 1}$, lower than 0.7 , for which the stepdown plastic zone size is approximately half the initial high load plastic zone size. For the load sequence with the stress
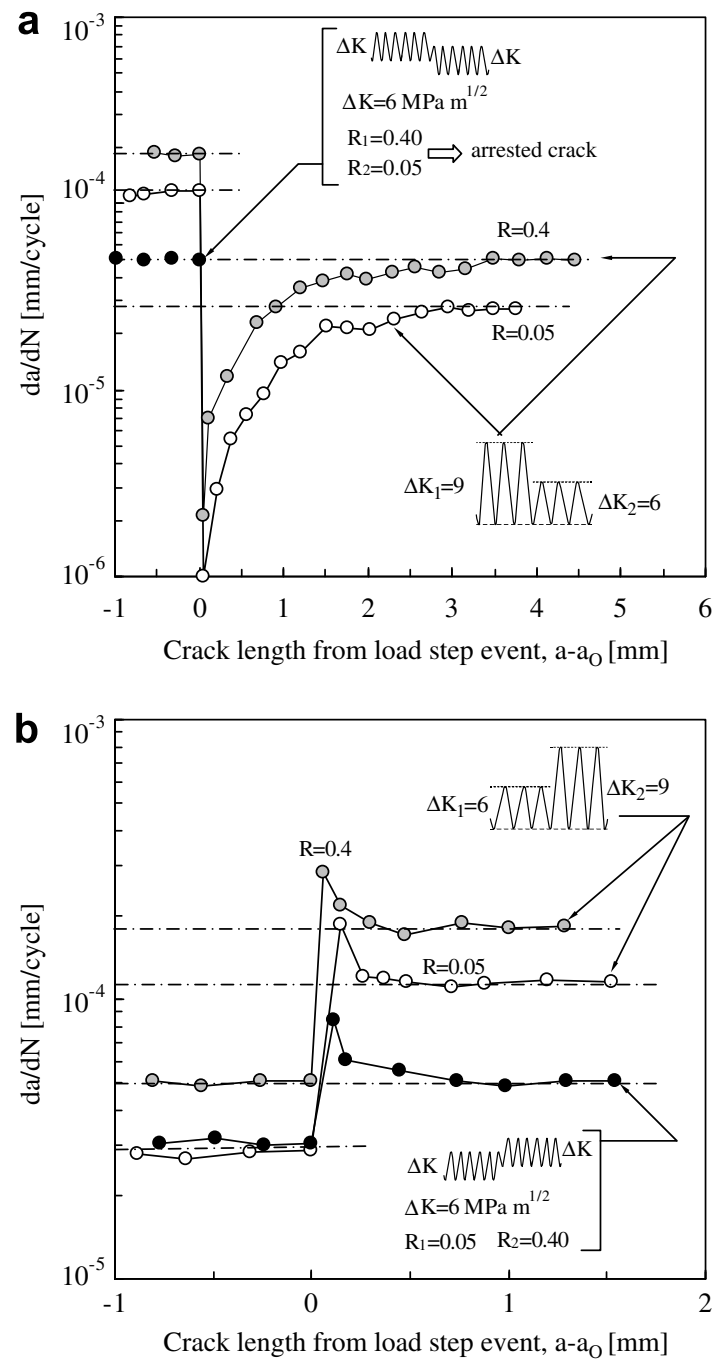

Fig. 6. Influence of the stress ratio in block loading: (a) Hi-Lo blocks and (b) Lo-Hi blocks.

ratio reduction presented in Fig. $6 \mathrm{a} K_{\max 2} / K_{\max 1}=0.63$ $\left(\Delta K_{2} / \Delta K_{1}=1\right)$. Therefore, the value of $K_{\max 2} / K_{\max 1}=0.7$ seems to be more suitable than the originally mention $\Delta K_{2} / \Delta K_{1}$ ratio [21] below which non-propagating crack will occur.

Fig. $6 \mathrm{~b}$ shows that, similar to the observed behaviour under Hi-Lo block sequences, the acceleration due to a load step-up decreases with increasing stress ratio, i.e., decreases with increasing mean stress (see Table 3 ). The load sequence with a stress ratio increase from $R_{1}=0.05$ to $R_{2}=0.4$ showed higher initial crack acceleration than the other Lo-Hi blocks analysed.

\subsection{Crack closure}

Figs. $7 \mathrm{a}$ and $\mathrm{b}$ illustrate the typical crack closure response obtained following $\mathrm{Hi}-\mathrm{Lo}$ and $\mathrm{Lo}-\mathrm{Hi}$ block sequences, respectively. The obtained data are plotted in terms of the normalized load ratio parameter $U$, calculated by Eq. (11), against the crack length from load step 

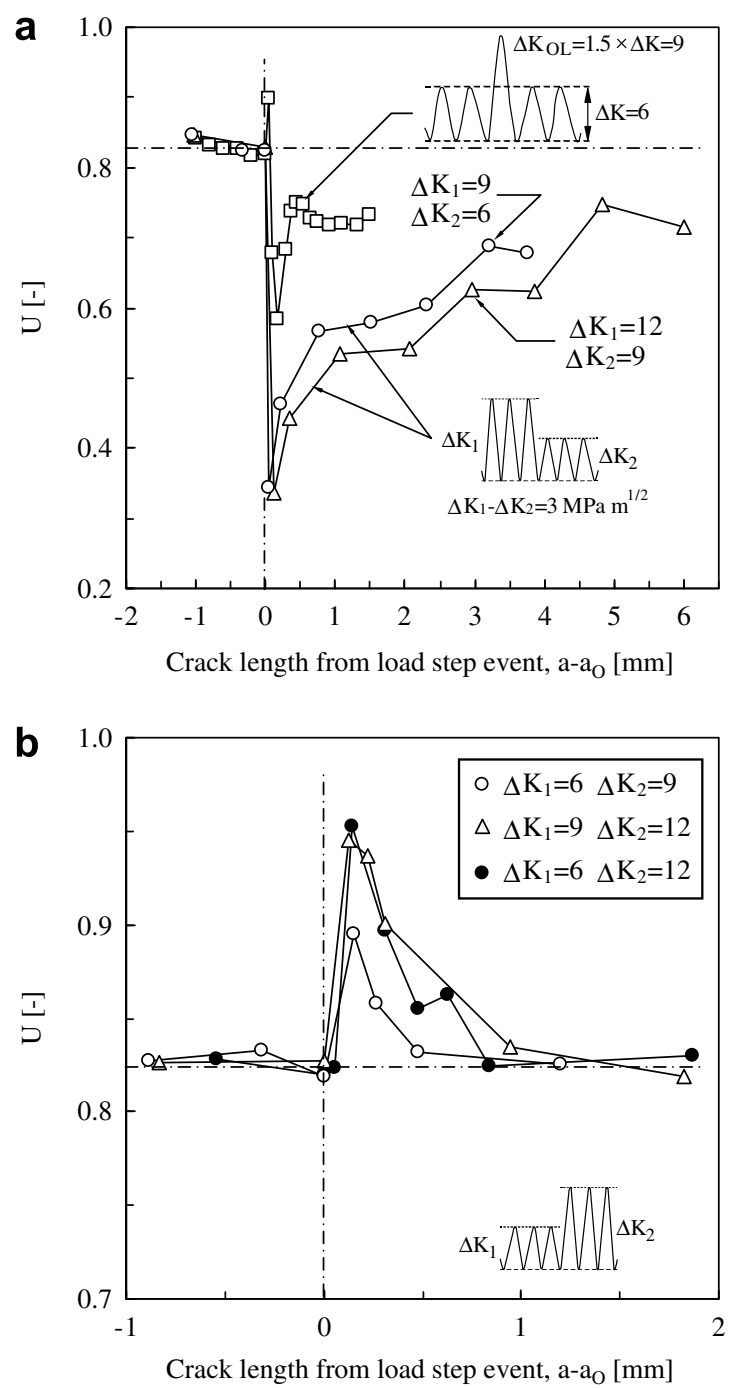

Fig. 7. Typical crack closure response in block loading: (a) load stepdown and (b) load step-up.

event, $a-a_{\mathrm{O}}$, i.e., $a^{*}$. This figure presents crack closure experimental measurements corresponding to crack growth rates depicted in Fig. 5, showing, in this way, the crack closure variation due to the magnitude and position of the load step. The crack closure level after the equivalent single tensile overload is also superimposed in Fig. 7a for comparison.

It is clear that the crack closure data presented show basically the same trend as the corresponding experimentally observed crack growth rate response. Prior to the load step the $U$ parameter at the baseline loading level is relatively stable $(U \approx 0.84)$. After load step-down $U$ drops, while after load step-up this parameter rapidly increases. For both load sequences, this initial phase is followed by a period where parameter $U$ tends gradually towards the stable crack closure level. Contrary to the behaviour observed after overloading, under Hi-Lo block sequences the decrease in $U$ towards the minimum value is immediate after load step-down. Therefore, the variation of the crack closure level is in agreement with the tran- sient crack growth behaviour observed under this load sequence.

Under Hi-Lo block sequences, the reduction in load leads to increased closure levels probably due to the larger plastic zone induced by the high block, which causes a decrease of crack growth rates to values well below the steady-state level expected for the lower block. This effect is similar to that observed in single peak overloads in the analysed alloy $[5,19]$ as well as in steels [2,13]. However, for a Hi-Lo block, the load step-down plastic zone and hence the near tip crack closure are imposed at the values corresponding to the higher block, the retardation is therefore always immediate. For a low-high block, as evident from the crack closure measurements, the initial acceleration of crack growth is due to removal of near tip closure by the load step itself.

Fig. 7a shows that under Hi-Lo block sequences with equal decrease in load $\left(3 \mathrm{MPa} \mathrm{m}^{1 / 2}\right)$, crack closure level increases with the initial $\Delta K$ level, $\Delta K_{1}$. When $\Delta K_{1}$ increased from 9 to $12 \mathrm{MPa} \mathrm{m}{ }^{1 / 2}$, parameter $U$ decreased approximately $10 \%$ during the crack growth rate recovering period. However, the value of the effective range of $K, \Delta K_{\text {eff }}$, corresponding to the load step with a final $\Delta K$ level, $\Delta K_{2}$, of $9 \mathrm{MPa} \mathrm{m}{ }^{1 / 2}$ is kept approximately $35 \%$ above the $\Delta K_{\text {eff }}$ associated to the load step with $\Delta K_{2}=6 \mathrm{MPa} \mathrm{m}^{1 / 2}$. Therefore, in spite of the higher crack closure level observed for the greater $\Delta K_{1}$ value, due to the larger monotonic plastic zone induced by the high block, the quickest crack growth rate recovering observed for the load step with $\Delta K_{1}=12 \mathrm{MPa} \mathrm{m}^{1 / 2}$ and $\Delta K_{2}=9 \mathrm{MPa} \mathrm{m}^{1 / 2}$ (see Fig. 7a and Table 3 ) is supported by the $\Delta K_{\text {eff }}$ corresponding to the higher $\Delta K_{2}$ value. Fig. $7 \mathrm{a}$ also shows that the crack closure level under Hi-Lo block sequences is always above the level observed after the equivalent single tensile overload.

The variation of parameter $U$ under Lo-Hi block sequences depicted in Fig. 7b shows a reduction of the closure level, and, simultaneously, a larger transition period with increasing $\Delta K_{2}$. The crack closure level after Lo-Hi block sequences applied with different load step-up magnitude and equal final $\Delta K\left(12 \mathrm{MPa} \mathrm{m}^{1 / 2}\right)$ seems to be slightly higher under the load step with lower load variation, which would be in agreement with the observed increase in crack acceleration with $\Delta K_{1}$ (see Fig 5b). However, the parameter $U$ values under these two load steps are similar, and, therefore, a definitive conclusion is not possible beyond experimental uncertainty.

It is important to notice that, similarly to the observed after overloading, under Hi-Lo block sequences the stable crack closure level observed before the load step was not attained after the crack growth rate reached the steadystate level corresponding to $\Delta K_{2}$ (see Fig. 7a). In order to highlight this behaviour the experimental load step-down crack growth transients can be compared with crack growth rates inferred from remote closure measurements and the $\mathrm{d} a / \mathrm{d} N$ versus $\Delta K_{\text {eff }}$ relation for the material, which was determined in previous work [5] as 


$$
\frac{\mathrm{d} a}{\mathrm{~d} N}=1.23 \times 10^{-7}\left(\Delta K_{\text {eff }}\right)^{3.39} \text { for } 2.5 \leqslant \Delta K_{\text {eff }} \leqslant 12
$$

where $\mathrm{d} a / \mathrm{d} N$ and $\Delta K_{\text {eff }}$ are in $\mathrm{mm} /$ cycle and $\mathrm{MPa} \mathrm{m}^{1 / 2}$, respectively.

The crack growth rates inferred directly from the closure measurements, using the conventional Elber's closure approach Eq. (1), and Eq. (12), are compared with the experimental $\mathrm{d} a / \mathrm{d} N$ in Fig. 8.

Typically, the inferred directly from closure measurements and experimental crack growth rates show good agreement only until the crack growth rate is already recovering from the minimum value. Beyond this point predicted values tend to be lower than the experimental ones. Thus, similar to peak overloads [11-13,19], the phenomenon of partial crack closure is observed after load step-down. This behaviour is due to the crack surface contact at some distance from the crack tip, namely near the load step-down location. Therefore, also under Hi-Lo block sequences the crack opening load level indicated by a far field gauge
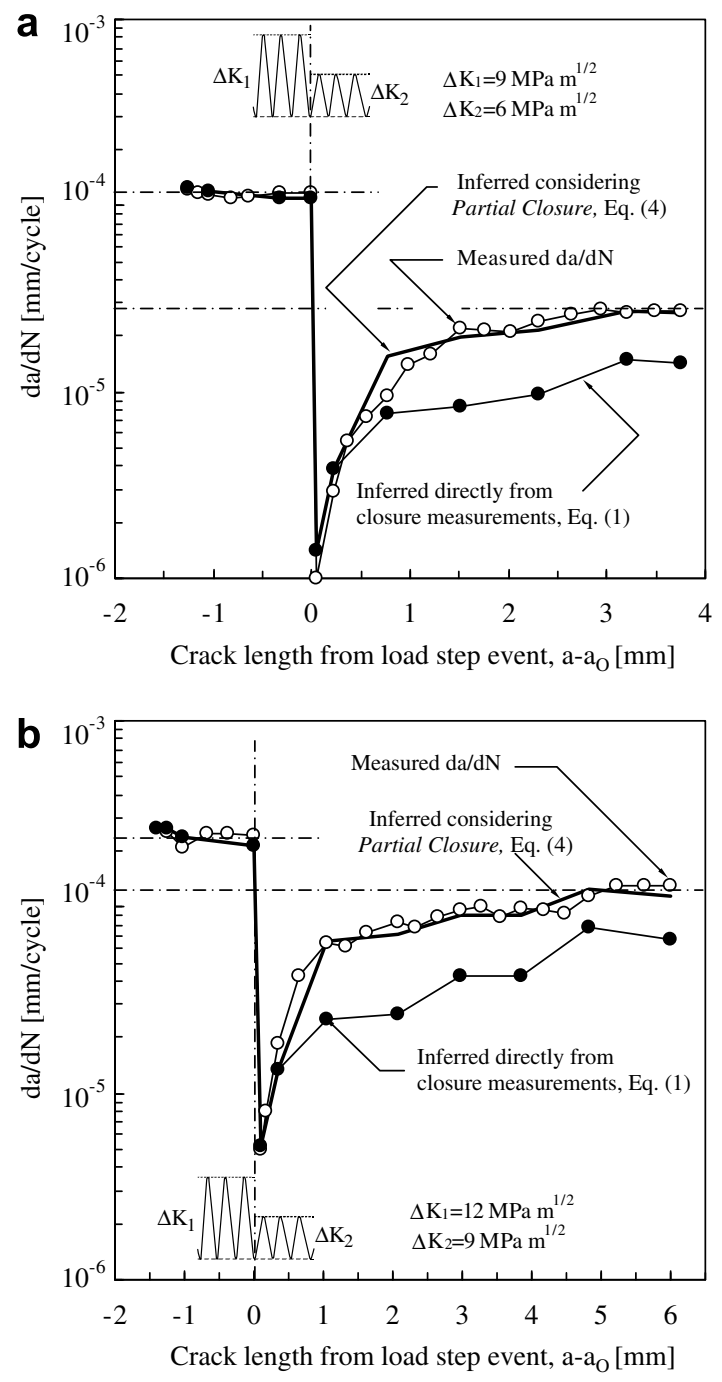

Fig. 8. Comparison of predicted from closure measurements and observed crack growth rates: (a) $\Delta K_{2} / \Delta K_{1}=0.67$ and (b) $\Delta K_{2} / \Delta K_{1}=0.75$. (entire crack open) is not necessarily the actual crack opening load.

The appearance of the discrepancy some time after maximum retardation was also observed after a single tensile overload $[5,12,19]$ and is consistent with the plasticityinduced crack closure argument. It is suggested that an additional increase in crack length is necessary after the minimum value of the fatigue crack growth rate is reached, so that the deformation mismatch between the plastically stretched material and the surrounding elastic material can be less severe at the crack tip than at the load stepdown location. Afterwards the crack can be open at the tip and closed at the load step-down location.

The crack growth rates inferred using Eq. 4 for crack lengths higher than half the monotonic plastic zone established by the high block are also superimposed in Fig. 8. It is important to notice that full closure is observed for crack lengths less than $r_{\mathrm{p}} / 2$ and, thus, Eq. (1) must be used. It is clear that the enhanced partial closure model, Eqs. (4) and (10), is able to correctly account for the partial closure effect under Hi-Lo block sequences, inclusively during the transition period. Therefore, for variable amplitude fatigue crack growth predictions based upon experimental crack closure measurements that are made remotely from the crack tip, the partial crack closure effect must be considered.

\section{SEM observations}

Figs. 9a-c show some typical features of the fatigue fracture surfaces of the specimens tested under Hi-Lo block sequences. The images presented were obtained at the position close to the centre of the specimens. The crack direction is from bottom to top in all figures.

Fig. 9a shows a low magnification image of the fatigue fracture surface of a specimen tested under a Hi-Lo block sequence with $\Delta K_{1}=12, \Delta K_{2}=9 \mathrm{MPa} \mathrm{m}{ }^{1 / 2}$ and $R=0.05$. This figure shows a typical dark band observed following the load step-down in the Hi-Lo block sequence. This band could be followed continuously over the full thickness of the specimen. Generally the crack front corresponding to the load step-down cycle was slightly bowed $(<0.3 \mathrm{~mm}$ in all cases). Curved crack fronts following a peak overload were also observed for this alloy [19] and were also reported for steels by Shuter and Geary [2].

High magnification images of the fracture region before load step-down and of the dark band are presented in Fig. $9 \mathrm{~b}$ and c, respectively, to highlight differences between these zones. Typical fatigue fracture surfaces of AlMgSilT6 alloy have a relatively chaotic wavy appearance and the fracture path did not seem to be the result from a single mechanism of fracture (see Fig. 9b). The crack propagates on multiple plateaus that are at different elevations with respect to each other. The plateaus (labelled A) are joined either by tear ridges or walls (labelled B). These relatively smooth areas consisted predominantly of transgranular fatigue propagation containing fairly well-developed stria- 

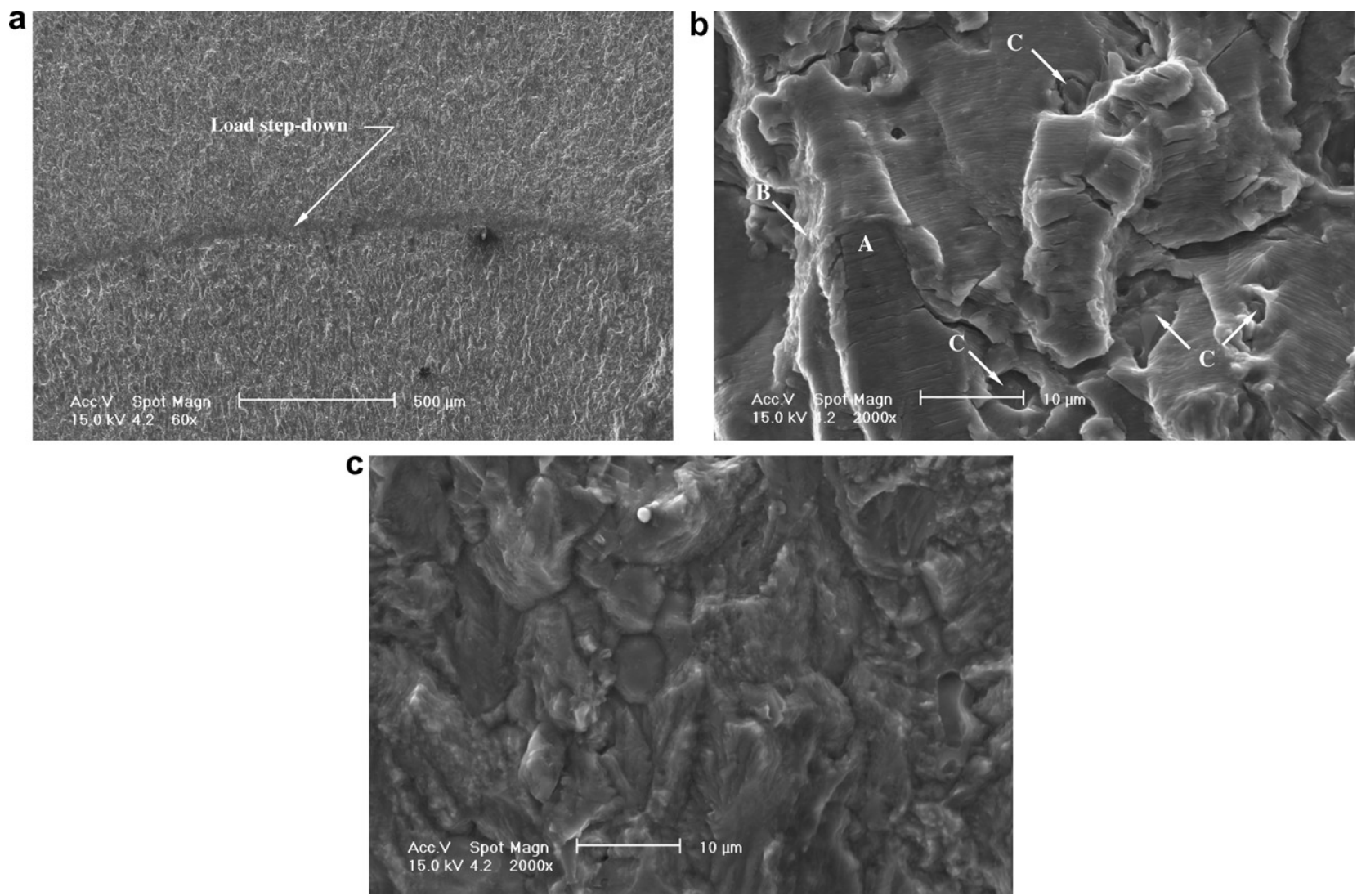

Fig. 9. SEM images of fracture surfaces, $\Delta K_{1}=12 \mathrm{MPa} \mathrm{m}^{1 / 2}, \Delta K_{2}=\mathrm{MPa} \mathrm{m}{ }^{1 / 2}$ and $R=0.05$ : (a) typical dark band observed following load step-down, (b) high magnification image of fracture region before load step-down and (c) high magnification image of dark band zone.

tions with evidence of some secondary cracking and widely dispersed microvoid formation around second-phase particles (labelled C). These observations are consistent with those reported for similar alloys [29].

It can be clearly seen, by comparison between Fig. 9b and $\mathrm{c}$, that the dark band fracture region (adjacent to load step-down) has less irregular surface topography than the region before load variation (phase of stable crack growth). Furthermore, Fig. 9c shows a smeared fracture zone in the whole crack front, denoting increased contact between crack faces. These observations provide good evidence for the enhancement of crack closure following load stepdown.

\section{Conclusions}

From the experimental study on fatigue crack growth behaviour in AlMgSi1-T6 alloy under block loading, the following concluding remarks can be drawn:

1. The effect of Hi-Lo block sequences is similar to that observed for peak overloads. However, for this load sequence the retardation is always immediate. Lo-Hi sequences produce crack acceleration.

2. Under Hi-Lo blocks, increasing the difference between the initial stress intensity and the final stress intensity range increases crack growth retardation. Furthermore, for equal step-down in loads, retardation increases with the decrease of the lower $\Delta K$. Under Lo-Hi blocks acceleration increases with the final $\Delta K$.

3. The retardation and acceleration effects observed in Hi-Lo and Lo-Hi block sequences, respectively, are reduced with increasing stress ratio.

4. There is a good correlation between crack closure and crack growth transients in block loading when the partial closure phenomenon is correctly account for. Therefore, plasticity-induced crack closure plays an important role on the load interaction effects observed in aluminium alloys.

\section{Acknowledgement}

The authors would like to acknowledge POCTI programme, Project 1999/EME/32984, for funding the work reported.

\section{References}

[1] Ward-Close CM, Blom AF, Richie RO. Mechanisms associated with transient fatigue crack growth under variable amplitude loading: an experimental and numerical study. Eng Fract Mech 1989;32: $613-38$. 
[2] Shuter D, Geary W. Some aspects of fatigue crack growth retardation behaviour following tensile overloads in a structural steel. Fatigue Fract Eng Mater Struct 1996;19:185-99.

[3] Elber W. The significance of fatigue crack closure. In: Damage tolerance in aircraft structures. ASTM STP, vol. 486. ASTM; 1971. p. $230-42$.

[4] Stofanak RJ, Wertzberg RW, Miller G, Jeccard R, Donald K. On the cyclic behavior of cast and extruded aluminium alloys, Part A: fatigue crack propagation. Eng Fract Mech 1983;17:527-39.

[5] Borrego LP, Ferreira JM, Costa JM. Fatigue crack growth and crack closure in an AlMgSi alloy. Fatigue Fract Eng Mater Struct 2001;24:255-66.

[6] Garz RE, James MN. Observations on evaluating fatigue crack closure from compliance traces. Int J Fatigue 1989;11:437-40.

[7] Hertzberg RW, Newton CH, Jaccard R. Crack closure: correlation and confusion. In: Newman Jr JC, Elber W, editors. Mechanics of fatigue crack closure. ASTM STP, vol. 982. Philadelphia (PA): ASTM; 1988. p. 139-48.

[8] Chen DL, Weiss B, Stickler R. Contribution of the cyclic loading portion below the opening load to fatigue crack growth. Mater Sci Eng A 1996;208:181-7.

[9] Robin C, Louah M, Pluvinage G. Influence of the overload on the fatigue crack growth in steels. Fatigue Fract Eng Mater Struct 1983;6:1-13.

[10] Dexter RJ, Hudak SJ, Davidson DL. Modelling and measurement of crack closure and crack growth following overloads and underloads. Eng Fract Mech 1989;33:855-70.

[11] Fleck NA. Influence of stress state on crack growth retardation. In: Fong JT, Fields RJ, editors. Basic questions in fatigue: volume 1, ASTM STP, vol. 924. Philadelphia (PA): ASTM; 1988. p. 157-83.

[12] Shercliff HR, Fleck NA. Effect of specimen geometry on fatigue crack growth in plane strain - II overload response. Fatigue Fract Eng Mater Struct 1990;13:297-310.

[13] Shin CS, Hsu SH. On the mechanisms and behaviour of overload retardation in AISI 304 stainless steel. Int J Fatigue 1993;15:181-92.

[14] Paris PC, Tada H, Donald JK. Service load fatigue damage - a historical perspective. Int J Fatigue 1999;21(Suppl.):S35-46.

[15] Donald K, Paris PC. An evaluation of $\Delta K_{\text {eff }}$ estimation procedures on 6061-T6 and 2024-T3 aluminium alloys. Int J Fatigue 1999;21 (Suppl.):S47-57.

[16] Vasudevan AK, Sadananda K, Louat N. A review of crack closure, fatigue crack threshold and related phenomena. Mater Sci Eng A 1994;188:1-22.
[17] Newman Jr JC. Analysis of fatigue crack growth and closure near threshold conditions for large-crack behavior. In: Newman Jr JC, Piascik RS, editors. Fatigue crack growth thresholds, endurance limits, and design. ASTM STP, vol. 1372. West Conshohocken (PA): ASTM; 1999. p. 1-25.

[18] Paris PC, Hermann L. Twenty years of reflection on questions involving fatigue crack growth, part II: some observations of crack closure. In: Backlund J, Blom AF, Beevers CJ, editors. Proceedings of the fatigue thresholds. Warley, UK: EMAS Ltd.; 1981. p. 11-32.

[19] Borrego LP, Ferreira JM, Costa JM. Evaluation of overload effects on fatigue crack growth and closure. Eng Fract Mech 2003;70:1379-97.

[20] Kujawski D. Correlation of long- and physically short-cracks growth in aluminium alloys. Eng Fract Mech 2001;68:1357-69.

[21] Sehitoglu H, McDiarmid DL. The effect of load step-down on fatigue crack arrest and retardation. Int J Fatigue 1980;2:55-60.

[22] Ng'Ang'a SP, James MN. Variable amplitude loading in En8 (080M40) steel: a detailed experimental study of crack growth. Fatigue Fract Eng Mater Struct 1996;19:207-16.

[23] Borrego LP, Abreu LM, Costa JM, Ferreira JM. Analysis of low cycle fatigue in AlMgSi aluminium alloys. Eng Failure Anal 2004;11:1321-31.

[24] ASTM E 647. Standard test method for measurements of fatigue crack growth rates. In: Annual book of ASTM standards, vol. 03.01. West Conshohocken (PA): ASTM; 2000. p. 591-630.

[25] Borrego LP, Costa JM, Silva S, Ferreira JM. Microstructure dependent fatigue crack growth in aged hardened aluminium alloys. Int J Fatigue 2004;26:1321-31.

[26] Allison JE, Ku RC, Pompetzki MA. A comparison of measurement methods and numerical procedures for the experimental characterization of fatigue crack closure. In: Newman Jr JC, Elber W, editors. Mechanics of fatigue crack closure. ASTM STP, vol. 982. Philadelphia (PA): ASTM; 1988. p. 171-85.

[27] Ohrloff N, Gysler A, Lütjering G. Fatigue crack propagation behaviour under variable amplitude loading. In: Petit J, Davidson DL, Suresh S, Rabbe P, editors. Fatigue crack growth under variable amplitude loading. Elsevier; 1988. p. 24-34.

[28] McDiarmid DL, Choy W, Lee TM. The effect of mean stress on delay in fatigue crack growth load stepdown. Int J Fatigue 1984;6:101-5.

[29] Bhandarkar MD, Lisagor WB. Metallurgical characterization of the fracture of aluminum alloys. In: Strauss BM, Cullen WH, editors. Fractography in failure analysis. ASTM STP, vol. 645. Philadelphia (PA): ASTM; 1978. p. 176-209. 